\title{
Evolution of self-sustained kinetic oscillations in the catalytic oxidation of propane over a nickel foil
}

\author{
V.V. Kaichev ${ }^{1,2, *}$, D. Teschner ${ }^{3}$, A.A. Saraev ${ }^{1,2}$, S.S. Kosolobov ${ }^{2,4}$, A.Yu. Gladky ${ }^{1}$, \\ I.P. Prosvirin ${ }^{1}$, N.A. Rudina ${ }^{1}$, A.B. Ayupov ${ }^{1}$, R. Blume ${ }^{3,5}$, M. Hävecker ${ }^{3,5}$, A. Knop-Gericke ${ }^{3}$, \\ R. Schlögl ${ }^{3}$, A.V. Latyshev ${ }^{4}$, V.I. Bukhtiyarov ${ }^{1,2}$ \\ ${ }^{1}$ Boreskov Institute of Catalysis, Lavrentiev Ave. 5, 630090 Novosibirsk, Russia \\ ${ }^{2}$ Novosibirsk State University, Pirogov Str. 2, 630090 Novosibirsk, Russia \\ ${ }^{3}$ Department of Inorganic Chemistry, Fritz Haber Institute, Faradayweg 4-6, D-14195 Berlin, Germany \\ ${ }^{4}$ Rzhanov Institute of Semiconductor Physics, Lavrentiev Ave. 13, 630090 Novosibirsk, Russia \\ ${ }^{5}$ Helmholtz Zentrum Berlin, BESSY II, Catalysis for Energy. D-12489 Berlin, Germany
}

\begin{abstract}
The evolution of self-sustained reaction-rate oscillations in the catalytic oxidation of propane over a nickel foil has been studied in situ using X-ray photoelectron spectroscopy coupled with on line mass spectrometry and gas chromatography. Changes in the effective surface area and in the catalyst morphology under reaction conditions have been examined by scanning electron microscopy and a krypton adsorption technique. It is shown that the regular kinetic oscillations arise under oxygen-lean conditions. $\mathrm{CO}, \mathrm{CO}_{2}, \mathrm{H}_{2}, \mathrm{H}_{2} \mathrm{O}$, and propylene are detected as products. The conversion of propane oscillates in a range from $1 \%$ to $23 \%$. During the half-periods with high activity, the main reaction pathway is the partial oxidation of propane: selectivity toward $\mathrm{CO}$ achieves $98 \%$. In contrast, during the half-periods with low activity, the reaction proceeds through three competitive pathways: the partial oxidation of propane, the total oxidation of propane, and the dehydrogenation of propane to propylene. The driving force for the selfsustained kinetic oscillations is the periodic reoxidation of nickel. According to the Ni2 $p$ and O1s core-level spectra measured in situ, the high-active catalyst surface is represented by metallic nickel, whereas during the inactive half-periods the catalyst surface is covered with a thick layer of $\mathrm{NiO}$. The intensity of $\mathrm{O} 1 s$ spectra follows the oscillations of $\mathrm{O}_{2}$ in the gas phase during the oxidation of propane. It is found that during the induction period before the regular oscillations appear, a rough and porous structure develops because of strong reconstruction of the catalyst surface. The thickness of the reconstructed layer is approximately $10-20 \mu \mathrm{m}$. This process is accompanied with at least an 80 -fold increase in the effective surface area compared with a clean, non-treated nickel foil, which undoubtedly leads to a drastic increase in the number of active sites. We believe that it is the main reason for the induction period always being
\end{abstract}

\footnotetext{
* Corresponding author.

E-mail address: vvk@catalysis.ru (V.V. Kaichev)
} 
observed before the appearance of self-sustained oscillations in the catalytic oxidation of light hydrocarbons over catalysts with a low specific surface area (single crystals, foils, or wires). Moreover, without such reconstruction, the oscillations cannot arise due to low activity of such catalysts.

Keywords: Heterogeneous catalysis; Propane oxidation; Nickel; Self-sustained rate oscillations

\section{Introduction}

Nonlinear behavior, such as self-sustained reaction-rate oscillations, is a widespread phenomenon in heterogeneous catalysis. To date the self-sustained kinetic oscillations have been observed in approximately 40 catalytic reactions in a wide pressure range from ultrahigh vacuum up to atmospheric pressure over all types of catalysts including single crystals, polycrystalline foils, wires, foams, and supported catalysts [1-4]. A wide class of these reactions is the oxidation of hydrocarbons over transition metals. For instance, self-sustained rate oscillations have been noted in the oxidation of methane, ethane, propane, and butane over supported and unsupported catalysts based on $\mathrm{Ni}, \mathrm{Co}, \mathrm{Pd}, \mathrm{Pt}, \mathrm{Rh}$, and $\mathrm{Ru}$ [5-24]. The distinctive features of these oscillations are their long periods, ranging from several seconds to tens of minutes, and an induction period before the appearance of the regular oscillations. These oscillations arise under oxygen-lean conditions. For instance, the oscillations in the oxidation of propane over Ni exist when the propane/oxygen molar ratio ranges from $3 / 1$ to $15 / 1$ [25]. Besides, strong reaction-induced changes in the catalyst morphology are observed during the oscillations [11, 15, 23].

It is generally thought that these oscillations arise from repetitive cycles of oxidation and reduction of the metal surface, and the detailed nature of the oscillations depends on the relative activities of the oxidized and reduced surfaces. Recently, it has been confirmed directly by the results of in situ studies [25-27]. However, the reasons that initiate the appearance of these oscillations are not clear yet. The aim of the present work was to investigate in detail the evolution of self-sustained rate oscillations in the oxidation of propane over nickel. Earlier, it was found that the regular oscillations in this catalytic system appear at a pressure of about 1 mbar [23]. It allowed us to apply surface sensitive techniques such as X-ray photoelectron spectroscopy (XPS) coupled with on line mass spectrometry (MS) and gas chromatography (GC) for the in situ study of this phenomenon [25]. XPS is a powerful tool of the heterogeneous catalysis to investigate both the surface composition and the nature of adsorbed species, while mass spectrometry can provide the abundance of products and reactants in the gas phase $[28,29]$. The usage of gas chromatography allows us to measure the conversion of reagents and selectivity toward the main reaction products during the oscillations. Also, the effective surface 
area and the morphology of nickel foils used as the catalyst were examined by scanning electron microscopy (SEM) and a krypton adsorption technique before and after the appearance of the regular oscillations.

\section{Experimental section}

The in situ experiments were performed at the Innovative Station for In Situ Spectroscopy (ISISS) beamline at the synchrotron radiation facility BESSY II (Berlin, Germany). The experimental station was described in detail elsewhere [29]. In short, this station is equipped with an electron energy analyzer PHOIBOS-150 (SPECS Surface Nano Analysis GmbH), a gas cell, and a system of electron lenses. The lens system was combined with three differential pumping stages that provided UHV conditions in the electron energy analyzer even when the pressure in the gas cell reached 10 mbar. The high brilliance of the synchrotron radiation combined with a short travel length of the photoelectrons through a "high-pressure" zone in the gas cell allowed us to obtain high-quality core-level spectra under flow conditions with time resolution of approximately 100 seconds.

In all the experiments, rectangular pieces of a $0.125 \mathrm{~mm}$ thick nickel foil (purity $99.99 \%$, Advent Research Materials Ltd.) were used as the catalyst. In the XPS experiments, a sample $9 \times 9 \mathrm{~mm}$ in size was mounted on a sapphire sample holder between a SiC plate and a stainless steel plate, which had a hole of $8 \mathrm{~mm}$ in diameter for measuring the core-level spectra of the catalyst surface. The sample was heated from the rear via the $\mathrm{SiC}$ plate with a NIR semiconductor laser $(\lambda=808 \mathrm{~nm})$. This system allowed us to heat the sample up to $1000{ }^{\circ} \mathrm{C}$ in vacuum. The sample temperature was monitored with a K-type thermocouple spot-welded directly to the foil edge. The station was also equipped by an extractor type ion source operated at $10^{-4}$ mbar of argon, which can be used for cleaning the surface of samples under study.

The propane and oxygen flows were regulated separately with mass-flow controllers (Bronkhorst High-Tech BV). The total pressure of the reactant mixture in the gas cell was measured with a MKS type 121A baratron (MKS Instruments Inc.). During the experiments, the total pressure in the gas cell was kept at a constant level of 0.5 mbar using a special automatic pumping system [29]. The gas-phase composition was monitored continuously with an on line quadrupole mass spectrometer Prizma QMS-200 (Pfeiffer Vacuum GmbH) connected through a leak valve to the gas cell. The GC analysis was made using an on line four-channel micro gas chromatograph CP-4900 (Varian Inc.) equipped with thermal conductivity detectors. Because the gas chromatograph can sample gas mixtures only at atmospheric pressure, in our experiments the sampling was performed in the outlet of the automatic pumping system consisted of a turbo pump ventilated by dry $\mathrm{N}_{2}$ and coupled with a membrane pump which provided the compression 
of the gas mixture from 0.5 mbar to 1 bar. Before the experiments, the gas chromatograph was calibrated with respect to propane, oxygen, and the main reaction products: $\mathrm{C}_{3} \mathrm{H}_{6}, \mathrm{CO}, \mathrm{CO}_{2}, \mathrm{H}_{2}$, and $\mathrm{H}_{2} \mathrm{O}$. The selectivity $\left(S_{i}\right)$ toward a product $i$ (propylene, $\mathrm{CO}$, or $\mathrm{CO}_{2}$ ) was calculated using the partial pressures of products $\left(p_{i}\right)$ determined by GC and inverse values of the stoichiometric coefficients $\left(k_{i}\right)$ according to a formula as follows:

$$
S_{i}=k_{i} \times p_{i} / \Sigma\left(k_{j} \times p_{j}\right) \times 100 \%,
$$

where $k_{i}=1 / 3$ for $\mathrm{CO}$ and $\mathrm{CO}_{2}$, and $k_{i}=1$ for $\mathrm{C}_{3} \mathrm{H}_{6}$.

All the photoelectron spectra were collected at the normal emission at the constant pass energy of $10 \mathrm{eV}$; their intensities were normalized to the ring current. The Ni2p $3 / 2, \mathrm{O} 1 \mathrm{~s}$, and $\mathrm{C} 1 \mathrm{~s}$ core-level spectra were obtained with photon energies of 1050,730 , and $485 \mathrm{eV}$, respectively, that provided the same kinetic energy (approximately $200 \mathrm{eV}$ ) for each region and, correspondently, the same analysis depth of approximately $1.7 \mathrm{~nm}$. In all cases, the valence-band spectra were acquired at the same photon energy as an adjustable spectrum. The positions of the photoelectron peaks on the binding energy scale were referenced to the Fermi edge of nickel in the metallic state.

All spectra were analyzed using the CasaXPS software [30]. A Shirley-type background was subtracted from each spectrum. The line shape used for fitting the Ni2 $p_{3 / 2}$ spectra of nickel in the oxidized state and the O1s spectra was the product of Lorentzian and Gaussian functions. An asymmetric, so-called LF [30] line shape was used for approximation of the Ni2 $p_{3 / 2}$ spectra of nickel in the metallic state. Note that the asymptotic form of the LF line shape is equivalent to the asymptotic form of the theoretical Doniach-Sunjic asymmetric line shape. However, this new line shape describes the asymmetric XPS peak more correctly than the conventional DoniachSunjic function does because the LF function is finite. The parameters of all peaks observed in the $\mathrm{Ni} 2 p_{3 / 2}$ and $\mathrm{O} 1 s$ spectra are summarized in supporting information, Table S1.

The effective surface area and the morphology of nickel foils before and after the appearance of the regular oscillations were examined using scanning electron microscopy and a gas adsorption technique. The catalytic testing of these foils was performed on a flow reactor equipped with a quadrupole mass spectrometer (see details elsewhere [22, 23]). Because the effective surface area of the samples was extremely small, we used $\mathrm{Kr}$ adsorption at $77 \mathrm{~K}$, which is a much more sensitive technique compared to conventional methods based on $\mathrm{N}_{2}$ and $\mathrm{Ar}$ adsorption. Isotherms of krypton adsorption were measured using an adsorption analyzer ASAP 2010 (Micromeritics Instrument Corp.). The surface area was calculated using the BrunauerEmmett-Teller (BET) method. The cross-section area of $\mathrm{Kr}$ molecules was assumed to be equal to $21.0 \AA^{2}$. Before measurements, all the samples were degassed at $200{ }^{\circ} \mathrm{C}$ in vacuum for $1.5 \mathrm{~h}$. The surface morphology was studied using a scanning electron microscope LEO 1430 (Carl 
Zeiss) and a focused ion beam (FIB) system Crossbeam 1540XB (Carl Zeiss). Surface profiling measurements were performed using a FIB "lift-out" technique for the cross section preparation of the sample under study [31]. For this purpose, a rectangular pit in a nickel foil was milled using a focused $\mathrm{Ga}^{+}$ion beam. Then the sample was tilted to a steep angle $\left(54^{\circ}\right)$, and SEM images of a sidewall of the pit were obtained.

\section{Results}

\subsection{In situ study}

In the first part of our study we investigated how the rate oscillations propagate in time during the catalytic oxidation of propane over a Ni foil using on line mass spectrometry and gas chromatography. Simultaneously, the catalyst surface was examined by X-ray photoelectron spectroscopy. In this experiment, at first, the surface of the Ni foil was cleaned by the Ar-ions sputtering $\left(2 \mathrm{keV}, 4 \mu \mathrm{A} / \mathrm{cm}^{2}\right)$ at room temperature for $1.5 \mathrm{~h}$. After that the sample was put into the gas cell and then a flow of a mixture of propane and oxygen was set. Finally, the Ni foil was heated to approximately $680{ }^{\circ} \mathrm{C}$ by the NIR laser using a fixed power regime. The oxygen flow was $0.5 \mathrm{sccm}$ and the propane flow was $4.5 \mathrm{sccm}$, which provided the propane/oxygen molar ratio of 9/1. According to our previous study [25], these conditions are appropriate for the appearance of the self-sustained kinetic oscillations. Indeed, the relaxation-type oscillations which can be described as fast evolution (jump up and jump down) between "low-active" and "high-active" states were detected by both mass spectrometry and gas chromatography. However, a long induction period was observed before the appearance of the regular oscillations.

The propagation of the oscillations in the production of hydrogen detected by mass spectrometry is shown in Fig. 1. One can see that most of the time the catalyst has low activity, and periodic peaks of $\mathrm{H}_{2}$ arise, indicating a transition of the catalyst to the high-active state. Irregular peaks with small amplitude are observed after 1.5 hours, whereas the first peak with high amplitude appears after 5.5 hours. The regular high-intense oscillations start only after 9 hours. $\mathrm{CO}$ forms simultaneously with $\mathrm{H}_{2}$, and as a result the shape and the position of $\mathrm{CO}$ peaks (not shown) coincide with the $\mathrm{H}_{2}$ peaks. According to the on line GC measurements, the conversion of propane oscillates in the range from $1 \%$ to $23 \%$. Propylene, $\mathrm{CO}, \mathrm{CO}_{2}, \mathrm{H}_{2}$, and $\mathrm{H}_{2} \mathrm{O}$ were detected by gas chromatography as products. It means that at least three catalytic reactions proceed after heating of the $\mathrm{Ni}$ foil in the reactant mixture: the partial oxidation of propane (1), the total oxidation of propane (2), and the direct dehydrogenation of propane to propylene (3):

$$
\begin{aligned}
& \mathrm{C}_{3} \mathrm{H}_{8}+1.5 \mathrm{O}_{2} \rightarrow 3 \mathrm{CO}+4 \mathrm{H}_{2}, \\
& \mathrm{C}_{3} \mathrm{H}_{8}+5 \mathrm{O}_{2} \rightarrow 3 \mathrm{CO}_{2}+4 \mathrm{H}_{2} \mathrm{O}, \\
& \mathrm{C}_{3} \mathrm{H}_{8} \rightarrow \mathrm{C}_{3} \mathrm{H}_{6}+\mathrm{H}_{2} .
\end{aligned}
$$


Certainly, the oxidative dehydrogenation of propane can also occur. Table 1 presents the conversion of propane and the selectivity toward the main reaction products measured in the experiment by gas chromatography in the characteristic moments.

After the high-intense oscillations commence, in the moments when the conversion of propane is high (around 18-23\%), the selectivity toward CO achieves 96-98\%, while the selectivity toward by-products, such as $\mathrm{CO}_{2}$ and $\mathrm{C}_{3} \mathrm{H}_{6}$, is only $1-3 \%$ (Table 1). According to our estimations, the selectivity toward $\mathrm{H}_{2}$ in this case ranges between $63 \%$ and $82 \%$, and we can speculate that the catalyst in the high-active state catalyzes the oxidation of propane to mainly $\mathrm{CO}$ and $\mathrm{H}_{2}$, but hydrogen partially is oxidized to water. In contrast, when the conversion is low (around 2-3\%), the selectivity toward $\mathrm{CO}$ is also low in a range of $59-75 \%$ and the selectivity toward $\mathrm{CO}_{2}$ and $\mathrm{C}_{3} \mathrm{H}_{6}$ varies in the ranges of 8-14 and 16-30, respectively (Table 1). Therefore, all three reactions mentioned above $(1-3)$ proceed over the catalyst in the low-active state.

Note that after heating the foil in the reactant mixture up to $680{ }^{\circ} \mathrm{C}$, the conversion of propane at first decreases from $0.6 \%$ to $0.1 \%$ and then increases slowly up to approximately $2 \%$ (Table 1). Simultaneously, a background MS signal of $\mathrm{H}_{2}$ slightly increases with time as well (Fig. 1). This clearly indicates that the catalyst surface under reaction conditions undergoes some irreversible modification. Evidently this modification is due to a change in the chemistry or morphology of near-surface layers of the Ni foil. To study the chemical changes in the catalyst surface, the XPS analysis was performed in situ in the key points simultaneously with MS and GC measurements. The corresponding Ni2 $p_{3 / 2}$ and $\mathrm{O} 1$ s core-level spectra are shown in Fig. 2.

The Ni2 $p_{3 / 2}$ spectrum obtained in vacuum after the Ar-ions sputtering contains a sharp peak at $852.6 \mathrm{eV}$, which undoubtedly corresponds to nickel in the metallic state. In spite of the vexed question of the origin of two other weak peaks at 855.5 and $859.0 \mathrm{eV}$, they are typical of metallic nickel as well. Some authors assign these extra peaks to energy loss peaks due to plasmon excitations in metal $[32,33]$, while other authors attribute them to either a final-state shake-up process or an initial-state configuration-mixing effect [34, 35]. Simultaneously, three low-intense peaks are observed at 529.4, 531.4, and 533.1 eV in the O1s spectrum. The first peak can be attributed to chemisorbed oxygen species, whereas two other peaks can refer to some $\mathrm{C}-$ O-containing species or molecular water formed on the surface because of the adsorption of residual gases [36]. After setting the flow of the reactant mixture, the intensity of the O1s spectrum increases strongly, however, the spectrum contains the same three peaks with similar relative intensities. The $\mathrm{Ni} 2 p_{3 / 2}$ spectrum changes slightly. One can see an increase in the peak at $855.3 \mathrm{eV}$ due to the formation of a new state that might be associated with surface nickel atoms interacting with adsorbates. 
The spectra change significantly after heating the nickel foil in the reactant mixture. The $\mathrm{Ni} 2 p_{3 / 2}$ spectrum shifts to a higher binding energy, and some additional peaks appear, indicating the oxidation of nickel [25]. Certainly, the electronic configuration $3 d^{8} \mathrm{of} \mathrm{Ni}^{2+}$ ions is responsible for such a complex shape of the spectrum. According to theoretical analysis $[37,38]$, the formation of a hole in the $2 p$ core level in transition metals is accompanied by a strong Coulomb repulsion with the holes in the localized $3 d$ orbitals. As a consequence, the photo-ionization of $2 p$ electron is followed by a charge transfer from oxygen ligands to the $3 d$ shell of nickel, leading to the $\underline{c} 3 d^{9} L$ final state, where $\underline{c}$ and $L$ refer to the holes in the Ni2p core level and in the ligand band $(\mathrm{O} 2 p)$, respectively. Therefore, the lowest energy of photoelectron peak at $853.9 \mathrm{eV}$ corresponds to the $\underline{c} 3 d^{9} L$ final state. The broad satellite structure with a maximum at $860.9 \mathrm{eV}$, which is typical of $\mathrm{Ni}^{2+}$ compounds such as $\mathrm{NiO}, \mathrm{Ni}(\mathrm{OH})_{2}$, and $\mathrm{NiAl}_{2} \mathrm{O}_{4}[32,39,40]$, can be assigned to a mixture of unscreened photoemission with the $\underline{c} 3 d^{8}$ final state and screened photoemission with the $\underline{c} 3 d^{10} L^{2}$ final state $[37,38]$. It should be noted that in the Ni2p spectrum of $\mathrm{Ni}^{3+}$ such satellite structures are absent [40]. The satellite at $855.4 \mathrm{eV}$, which looks as a prominent shoulder of the main line, is interpreted in terms of nonlocal screening of the $2 p$ hole in the $\mathrm{NiO}$ structure $[37,38]$. The intensity of this peak is highly sensitive to the long-range ordering and, hence, it is the most characteristic feature of bulk NiO. This feature is typically observed in the spectra of thick NiO films, while it is absent in the spectra of monolayer NiO films [38]. This peak is also absent, for instance, in the $\mathrm{Ni} 2 p_{3 / 2}$ spectra of $\mathrm{Ni}(\mathrm{OH})_{2}$, etc. [32]. The $\mathrm{Ni} 2 p$ spectra of a clean $\mathrm{Ni}$ foil, a $\mathrm{NiO}$ film, and bulk $\mathrm{Ni}(\mathrm{OH})_{2}$ are presented in Fig. 3 for comparison. One can see that the Ni2 $p_{3 / 2}$ spectrum of the catalyst in the low-active state (Fig. 2, spectrum 4 ) is similar to the $\mathrm{Ni} 2 p_{3 / 2}$ spectrum of reference NiO. The only differences between the spectra are the small shift of the shake-up satellites by $0.1-0.2 \mathrm{eV}$ and the increase of $14 \%$ in the relative intensity of the main shake-up satellite at $855.5 \mathrm{eV}$ (Table S1). These minor differences suggest that the low-active state is similar to $\mathrm{NiO}$ but is probably defect rich and thus without the extended long-range order.

The formation of a thick NiO layer on the foil surface after heating in the reactant mixture is also confirmed by the O1s spectrum, which consists of two peaks. The first strong peak at $529.4 \mathrm{eV}$ undoubtedly corresponds to oxygen in the lattice of NiO. The second weak peak at $531.4 \mathrm{eV}$ can be attributed to hydroxyl groups. Indeed, bulk $\mathrm{NiO}$ and $\mathrm{Ni}(\mathrm{OH})_{2}$ are characterized by the O1s binding energy within the ranges of 529.5-530.2 and 531.2-531.6 eV, respectively $[39,41,42]$. In our experiments, the O1s peaks at 529.6 and $531.4 \mathrm{eV}$ were observed in the spectra of $\mathrm{NiO}$ and $\mathrm{Ni}(\mathrm{OH})_{2}$ (Fig. 3). It should be stressed that the peaks in the $\mathrm{Ni} 2 p_{3 / 2}$ and $\mathrm{O} 1 \mathrm{~s}$ spectra of the catalysts in the low-active state have a slightly larger width than the same peaks in 
the spectra of reference $\mathrm{NiO}$ (Table S1). This indicates that the nickel oxide formed on the catalyst surface under reaction conditions has a defective structure.

The $\mathrm{Ni} 2 p_{3 / 2}$ and $\mathrm{O} 1 \mathrm{~s}$ core-level spectra obtained after the high-intense oscillations commenced in the moments of high and low conversion of propane correspond to nickel in the metallic state and $\mathrm{NiO}$, respectively. Indeed, the spectra of the catalyst in the low-active state before and after the oscillations commenced do not differ and correspond mainly to $\mathrm{NiO}$ (Fig. 2). The Ni2 $p_{3 / 2}$ spectrum of the catalyst in the high-active state consists of a sharp peak at $852.6 \mathrm{eV}$ and weak peaks at 855.5 and $858.2 \mathrm{eV}$. The corresponding O1s spectrum consists of two weak peaks at 529.4 and $531.4 \mathrm{eV}$. The sharp peak at $852.6 \mathrm{eV}$ is attributed to nickel in the metallic state. It should be noted that in this case the satellite structure of the $\mathrm{Ni} 2 p_{3 / 2}$ spectrum is more prominent than that of the fresh foil (Fig. 2) but is less prominent than that of the clean Ni foil (Fig. 3). It is more probably that the intensity of the satellite structure is sensitive to the surface contaminates indicating that these peaks are originated from the surface and bulk plasmon excitations in metallic Ni. The amount of nickel carbide, which is characterized by a similar value of the $\mathrm{Ni} 2 p_{3 / 2}$ binding energy and can be formed under these reaction conditions, is negligible, because the $\mathrm{C} 1 \mathrm{~s}$ spectrum in this case does not exhibit any features at 282-283 eV that are typical of nickel carbide. Moreover, the $\mathrm{C} 1 \mathrm{~s}$ spectra acquired in the moments of high and low conversion of propane do not contain any features in the range between 281 and $290 \mathrm{eV}$. The C1s spectra are presented in Fig. S1 of the supporting information. Therefore, the O1s peaks at 529.4 and $531.4 \mathrm{eV}$ can be attributed to atomic oxygen and hydroxyl groups adsorbed mainly on metallic nickel. The presence of a small amount of $\mathrm{NiO}$ also cannot be excluded because according to the literature, the O1s binding energies of chemisorbed oxygen and oxygen in the lattice of $\mathrm{NiO}$ are almost the same differing by less than $0.3 \mathrm{eV}$ [42]. However, taking into account the shape of the $\mathrm{Ni} 2 p_{3 / 2}$ spectrum, the total amount of oxidized nickel in the surface and subsurface region in this case does not exceed $10 \%$.

In the next experiment the periodic oxidation and reduction of nickel in the near surface region are observed by XPS during the regular self-sustained reaction rate oscillations. In this case, we measure the time-resolved core-level spectra simultaneously with the gas phase composition by mass spectrometry. In full agreement with our previous study [25], it has been found that the high-active catalyst surface is represented by metallic nickel, whereas the catalyst surface is covered with a layer of $\mathrm{NiO}$ when the catalyst demonstrates the low activity in the oxidation of propane. The thickness of the NiO layer is at least $3 \mathrm{~nm}$ [25]. Correspondingly, when the catalyst passes from the low-active state to the high-active state, the integral intensity of the O1s spectra decreases, and vice versa, the reverse transition is accompanied with restoring of the integral intensity of the O1s spectra. This process is clearly demonstrated in Fig. 4. One 
can see that when the catalyst is in the high-active state, the concentration of oxygen in the gas phase is low, while the yield of $\mathrm{CO}$ is high. At the same time, the intensity of O1s spectra follows the oscillations of oxygen in the gas phase.

\subsection{Ex situ surface morphology and effective surface area measurements}

In the second part of our study, the surface morphology and the effective surface area of a nickel foil before and after the appearance of the oscillations are examined, providing new insights into the structural changes during the oscillation behavior of this catalytic system. As mentioned above, after heating a clean nickel foil in the reactant mixture to $680{ }^{\circ} \mathrm{C}$, the conversion of propane at first slightly decreases and then slowly increases (Table 1). Taking into account the XPS data and the fact that the activity of nickel in the metallic state is higher than the activity of nickel oxide, we can postulate that the conversion of propane undoubtedly decreases because of the oxidation of nickel in the first moment. However, the following increase in the activity cannot be caused by chemical changes in the near surface region of the catalyst, because the Ni2p and O1s core-level spectra do not exhibit any new features (Fig. 2). Moreover, it is not clear why the $\mathrm{H}_{2}$ peaks strongly increase after the induction period (Fig. 1). More probably, this effect can be caused by strong reaction-induced changes in the catalyst morphology, which in part is accompanied with the increase in the effective surface area. To confirm this hypothesis, the morphology of the nickel foils is examined by scanning electron microscopy. It has been found that the surface of nickel foil after the Ar-ion sputtering and heating in vacuum to $1000{ }^{\circ} \mathrm{C}$ is mainly smooth and flat (images not shown), although some textural damages caused by the manufacturing process are observed. In the precision SEM images, irregular hill-and-valley structures can be discerned. Such morphology is similar to that reported in the literature for a clean polycrystalline metal surface [43-45]. In contrast, after a treatment in the reactant mixture, the surface becomes very rough (Fig. 5). It should be noted that the treatment is performed in the flow reactor $[22,23]$ in order to increase the reaction pressure and temperature. Previously, we have shown that the duration of the induction period depends on reaction conditions and decreases strongly with increasing temperature and pressure [23]. In these experiments, the pressure is $5 \mathrm{mbar}$, temperature is $710-740{ }^{\circ} \mathrm{C}$, and the propane/oxygen ratio is $9 / 1$. Under these conditions, the induction period is approximately $30 \mathrm{~min}$ that allows us to accelerate the investigations significantly.

Fig. 5 shows typical plan-view and cross-sectional SEM images of the nickel foil treated in the reactant mixture for 2 hours at $740{ }^{\circ} \mathrm{C}$ during the self-sustained kinetic oscillations. The lowmagnification image (Fig. 5a) reveals excrescences, which cover the surface uniformly. A characteristic size of the excrescences is 5-10 $\mu \mathrm{m}$. Previously, extensive reconstruction of the 
catalyst surface and development of similar excrescences that look like "cauliflowers" have been observed on Pt-Rh wires during the catalytic oxidation of ammonia [46, 47]. In our case, the reconstruction develops the structure that is more similar to "rock fill". Indeed, the image obtained at a higher magnification (Fig. 5b) clearly demonstrates that these excrescences have an irregular "rocky" shape. Moreover, the excrescences have a polycrystalline structure and consist of many crystallites with a size of several tens of nanometers. Well-defined steps, terraces, and crystallites with a cubic shape can be discerned as well (Fig. 5c). The last is typical of metallic nickel, which has the face-centered cubic structure.

A cross section image presented in Fig. 5d clearly demonstrates that the reconstruction affects the upper layer of the foil, approximately $10 \mu \mathrm{m}$ thick. This reconstructed layer has a roughened surface and, moreover, a number of submicron-sized pores can be observed. Obviously, such reconstruction results in an increase in the effective surface area. According to the krypton adsorption measurements, the effective surface area of the sample is approximately $380 \mathrm{~cm}^{2}$, while the total geometric surface area is only $4.8 \mathrm{~cm}^{2}$. It means that the effective surface area of the catalyst enlarges under these reaction conditions at least 80 -fold and this is the main reason why the $\mathrm{H}_{2}$ and $\mathrm{CO}$ peaks strongly grow in intensity after the induction period (Fig. 1). This finding clearly indicates that the evolution of self-sustained reaction-rate oscillations is likely to be associated with slow reversible transformation of the catalyst.

We have studied the reconstruction process in detail using scanning electron microscopy. For this purpose, three samples of a nickel foil are treated in the propane/oxygen mixture during 40, 130, and $260 \mathrm{~min}$ at slightly lower temperature near $710^{\circ} \mathrm{C}$. In this case, the induction period is approximately $30 \mathrm{~min}$. These samples are referred to as sample 1, sample 2, and sample 3, respectively. Characteristic plan-view SEM images are presented in Fig. 6. Comparison of the images reveals that the reconstruction occurs via two sequential stages in which different crystal structures are formed. The first stage, which concurs with the induction period, is the formation of a porous structure. On the surface of sample 1 one can see a lot of small pores with a size of approximately $0.5 \mu \mathrm{m}$, a part of which coalesced into large cavities (Fig. 6a,b,c). This structure is similar to a metal foam [48, 49] or to hierarchically sponge-like macro-/mesoporous titania [50]. Most probably, these pores are formed as a result of the cyclical oxidation and reduction of nickel, because the molar volumes of $\mathrm{NiO}$ and $\mathrm{Ni}$ differ significantly $\left(11.2\right.$ and $6.6 \mathrm{~cm}^{3} / \mathrm{mol}$, respectively). On the surface of sample 2, the porous structure is also observed; however, long treatment in the reactant mixture causes formation of new entities (Fig. 6d,e,f). These entities are similar to the excrescences depicted in Fig. 5a and have a characteristic size of approximately 10 $\mu \mathrm{m}$. The further treatment leads to the full disappearance of the porous structure, and the surface 
of sample 3 is covered by the excrescences (Fig. 6g,h,i) that are similar to the "rock fill" depicted in Fig. 5b.

Finally, to compare the reactivity of the nickel foil with the reactivity of real catalysts, we estimated the turnover frequency (TOF) of the oxidation of propane over $\mathrm{NiO}$ and over metallic nickel using the effective catalyst surface and the conversion of $\mathrm{C}_{3} \mathrm{H}_{8}$ measured by massspectrometry (Fig. 4). The TOF for nickel in the metallic state is $5.4 \mathrm{~s}^{-1}$, whereas the TOF for $\mathrm{NiO}$ is approximately $1.2 \mathrm{~s}^{-1}$. The latter value is in good agreement with the data reported by Corbo and Migliardini [51], who studied the partial oxidation of propane over $\mathrm{NiO} / \mathrm{Al}_{2} \mathrm{O}_{3}$ at a feed molar ratio $\mathrm{O}_{2} / \mathrm{C}$ equal to 0.53 . They found that the TOF at $800{ }^{\circ} \mathrm{C}$ varied in the range of $0.8-1.7 \mathrm{~s}^{-1}$, depending on the space velocity of the reactant mixture.

\section{Discussion}

Analysis of literature data indicates that the emergence of self-sustained kinetic oscillations in heterogeneous catalytic systems is mostly associated with changes in the structure or chemical composition of the surface and subsurface layers of catalysts [1]. For instance, the most famous mechanism, which is referred to in the literature as the reconstruction mechanism, was drawn from the results of ultrahigh-vacuum studies of the oxidation of $\mathrm{CO}$ over $\mathrm{Pt}$ single-crystal surfaces. This mechanism is based on the fact that the topmost metal layers of single crystals can reconstruct and that different reconstructions show different adsorption behavior. The first kinetic oscillations linked to an adsorbate-induced structural transformation of the surface were observed for the (100) crystal face of platinum in 1982. Ertl and co-workers [52] presented experimental evidence for this model in which the reversible $(5 \times 20) \leftrightarrow(1 \times 1)$ phase transition of the $\operatorname{Pt}(100)$ surface (which is associated with a sufficient variation of the oxygen sticking coefficient) is responsible for the self-sustained oscillations. Afterward, a cyclic transition of the well-ordered $(1 \times 2)$ missing-row surface phase into a disordered $(1 \times 1)$ state was detected during the self-sustained rate oscillations in the oxidation of $\mathrm{CO}$ over $\operatorname{Pt}(110)$ under flow conditions at pressures near $10^{-3}$ mbar [53].

The oscillations can also arise due to the faceting of the catalyst surface. Usually, the faceting is determined as a process that causes an initially flat, single-crystal surface to separate into two (or three) other surface orientations. The driving force of the faceting is minimization of the surface free energy. Surface reorganizes into lower energy configurations via the localized surface diffusion most likely without volatilization or any loss of mass. Of course, the dissolution of small atoms such as $\mathrm{H}, \mathrm{C}$, and $\mathrm{O}$ into the subsurface layers might induce the faceting as well [43-45]. Such structural transformations are associated with changes in the oxygen sticking coefficient and, hence, in the reactivity. The periodic switching between these 
states of low and high activity gives rise to the observed modulation of the reaction rate as it is observed in the oxidation of $\mathrm{CO}$ on $\mathrm{Pt}(110)$ under UHV conditions [1]. More recently, Vendelbo et al. [54], using in situ time-resolved high-resolution transmission electron microscopy coupled with mass spectrometry, have shown that periodic changes in the oxidation of $\mathrm{CO}$ at atmospheric pressure are synchronous with a periodic faceting of Pt nanoparticles. It means that this so-called faceting mechanism can exist in a wide pressure range from UHV to elevated pressures.

Two other popular mechanisms link the rate oscillations to a periodic deactivation of the catalyst surface because of either the accumulation of carbonaceous deposits or the formation of a surface oxide layer. The carbon mechanism was first suggested by Burrows et al. [55] and further developed by Collins, Sundaresan, and Chabal in 1985 [56]. The mechanism is based on the combination of the Langmuir-Hinshelwood surface reaction, a slow catalyst deactivation via the carbon deposition, and a reactive regeneration of these deactivated sites by oxygen. More recently, Figueroa and Newton [57] have shown that this mechanism describes well the oscillatory behavior of the oxidation of $\mathrm{CO}$ over rhodium at atmospheric pressure. They have found that the spontaneous oscillations during the oxidation of $\mathrm{CO}$ over $\mathrm{Rh} / \mathrm{Al}_{2} \mathrm{O}_{3}$ catalysts are due to the dissociation of $\mathrm{CO}$ followed by the subsequent adsorption and combustion of atomic carbon. The oxidation-reduction mechanism, which is also referred to as the STM mechanism, was developed by Sales, Turner, and Maple [58] in the early 1980s for the explanation of kinetic oscillations in the oxidation of $\mathrm{CO}$ on polycrystalline $\mathrm{Pt}, \mathrm{Pd}$, and $\mathrm{Ir}$ at near atmospheric pressure. They suggested that the self-sustained oscillations occur between two branches of the LangmuirHinshelwood surface reaction mechanism, and the slow oxidation and reduction of the metal surface layer induces the transition between these branches.

All the mechanisms mentioned above cannot predict the induction period before the appearance of regular oscillations. Moreover, we observe that the strong reconstruction of the catalyst surface affects several thousands of upper atomic layers of a $\mathrm{Ni}$ foil during the oscillations (Fig. 5). Besides, in contrast to the STM mechanism, the oscillations in the oxidation of propane over nickel are controlled by the reversible bulk oxidation of Ni to NiO. Indeed, in our experiments we note that not only the topmost metal layers is oxidized, but a thick NiO film forms and disappears periodically over the nickel foil during the oscillations in the oxidation of propane (Fig. 2). The high-active catalyst surface is represented by metallic nickel. The spontaneous transition from the high-active state to the low-active state is accompanied with the growth of the $\mathrm{NiO}$ film over the catalyst surface. In our previous in situ XPS study [25], it has been shown that a thickness of the $\mathrm{NiO}$ film is at least $3 \mathrm{~nm}$, which corresponds to at least 7 atomic layers. During the reverse transition, the catalyst surface undergoes the full reduction. The switching between the metallic and oxide states shows a significant decrease in the catalytic 
activity (Fig. 4). According to the simultaneous XPS and GC measurements (Fig. 2, Table 1), the activity of metallic nickel is approximately 10 times higher than that of $\mathrm{NiO}$. This, together with the variation in the product distribution observed for the high active and low active states, suggests the changes in the reaction mechanisms. We suppose that the Langmuir-Hinshelwood mechanism is realized for the propane oxidation over the metallic Ni surface, whereas the reaction over $\mathrm{NiO}$ follows the Mars-van Krevelen mechanism. In the latter case, the oxidation of propane by $\mathrm{NiO}$ lattice oxygen, leading to the reduction of nickel, is coupled with the subsequent reoxidation of the reduced surface by oxygen from the gas phase. On the metallic surface, the main reaction route is the partial oxidation of propane to $\mathrm{CO}$ and $\mathrm{H}_{2}$, while over the oxidized surface the partial oxidation of propane, the total oxidation of propane to $\mathrm{CO}_{2}$ and water as well as the dehydrogenation of propane to propylene occur.

A similar mechanism was previously proposed by Hendriksen and co-workers [59] for the rate oscillations in the oxidation of $\mathrm{CO}$ over $\operatorname{Pt}(110)$ and $\mathrm{Pd}(100)$ single crystals observed under near atmospheric pressure ( $\sim 0.5$ bar). The authors supposed that the rate oscillations were not due to the bistability in the Langmuir-Hinshelwood kinetics, but arose from the periodic switching between the low-reactive metallic surface and the high-reactive oxide surface. The reaction over metallic surface follows the Langmuir-Hinshelwood mechanism, whereas metal-tooxide transition changes it to the Mars-van Krevelen mechanism. However, afterward this mechanism was subjected to criticism. In contrast to results by Hendriksen et al. [59] obtained in the mbar pressure range, no surface oxides were detected by XPS on the $\operatorname{Pt}(110)$ surface during the oxidation of CO [60]. Therefore, some additional experiments are needed for explaining these discrepancies. At the same time, it seems that the STM mechanism, as well as the subsurface oxygen mechanism [61] based on the assumption that the rate oscillations in catalytic activity are caused by the variation of the oxygen sticking probability under the influence of subsurface oxygen species, is realized only under vacuum conditions. At elevated pressures, the self-sustained rate oscillations in catalytic oxidation reactions over transition metals are more probably to follow the redox mechanism based on the reversible bulk oxidation of the catalyst. In full agreement with this hypothesis, the mathematic modeling of the oxidation of methane over nickel confirmed that the rate oscillations can arise because of the periodic oxidation and reduction of nickel [62] and that metallic nickel in this reaction is more active than $\mathrm{NiO}$.

Hence, our experiments clearly demonstrate that the reaction rate oscillations in the catalytic oxidation of propane are originated from the reversible oxidation of $\mathrm{Ni}$ to $\mathrm{NiO}$ that is accompanied with changing the reaction mechanism from the Langmuir-Hinshelwood mechanism to the Mars-van Krevelen mechanism; metallic Ni in this reaction is more active than $\mathrm{NiO}$, at least under used conditions. This finding contradicts several recent reports on catalytic 
oxidation chemistry. Indeed, it is considered that late transition metal oxides such as $\mathrm{RuO}_{2}, \mathrm{PdO}$, and $\mathrm{IrO}_{2}$ are more active in the catalytic oxidation of $\mathrm{CO}$ and hydrocarbons than corresponding metals [63]. For example, Martin et al. [64] studied the oxidation of methane on $\operatorname{Pd}(100)$ and showed that the high activity was achieved when a two-layer oriented film of $\mathrm{PdO}(101)$ was formed on the palladium surface. Using DFT calculations, they showed that the presence of oxygen atoms directly below coordinatively unsaturated (cus) palladium atoms in the two-layer oxide film is crucial for efficient dissociation of methane. Unfortunately, the surface structure of $\mathrm{NiO}$ under reaction conditions is not yet fully understood and thus we cannot make definitive conclusions about the main reasons for the lower reactivity of $\mathrm{NiO}$ in comparison with metallic Ni. A possible reason for this could be a lack of cus-sites at the predominant facets of formed NiO. Differences in the electronic structure between $\mathrm{NiO}$ and $\mathrm{PdO}$ or $\mathrm{RuO}_{2}$ could also be important. Another important difference may arise from the energetics of extracting lattice oxygen from the oxides, which may even invert the reactivity order oxide-to-metal in this system.

It should be noted that some reactions indeed can proceed via both the LangmuirHinshelwood and the Mars-van Krevelen mechanisms depending on experimental conditions and a catalyst type [65-68]. For instance, the oxidation of methane over Pt-based catalysts proceeds via the Langmuir-Hinshelwood mechanism, whereas over Pd-based catalysts, the oxidation of methane proceeds via the Mars-van Krevelen mechanism under the same experimental conditions [65]. In the first case, platinum is mainly in the metallic state, while in the second case, small PdO particles form over the catalyst surface. It means that platinum in the metallic state is more stable in the oxidation of methane than platinum oxides, whereas a strong interaction of palladium with a support stabilizes $\mathrm{PdO}$ nanoparticles at the same reaction conditions. In contrast, both $\mathrm{Ni}$ and $\mathrm{NiO}$ are unstable in the oxidation of propane and the selfsustained kinetic oscillations controlled by the reversible bulk oxidation of $\mathrm{Ni}$ to $\mathrm{NiO}$ and switching the reaction mechanism appear under certain conditions.

The periodic reduction and oxidation of nickel under the reaction conditions lead to a formation of the rough and porous structure on the nickel foil (Figs. 5 and 6), which is developed because the molar volumes of $\mathrm{NiO}$ and $\mathrm{Ni}$ differ significantly. A thickness of this reconstructed nickel layer is approximately $10 \mu \mathrm{m}$. This process is accompanied with a significant increase in the effective surface area, which undoubtedly leads to a drastic increase in the number of active sites. According to our measurements, the effective surface area of the nickel foil during the oxidation of propane increased approximately 80 -fold. On the one hand, this effect provokes a long induction period before the regular oscillations appear (Fig. 1). On the other hand, without such reconstruction of the catalyst surface, the appearance of self-sustained regular oscillations 
in the catalytic oxidation of light hydrocarbons over catalysts with a low specific surface area (single crystals, foils, or wires) can be limited by a low rate of these reactions. It is more probably that the synchronization of separated oscillators over the catalyst surface proceeds via the gas and/or surface diffusion $[69,70]$. However, in both cases, increasing the reaction rate (or catalyst activity) leads to an increase in the feedback intensity and initiates the appearance of the regular self-sustained oscillations [71].

The reasons for the spontaneous transition between the active and inactive states, i.e. between metallic $\mathrm{Ni}$ and $\mathrm{NiO}$, are not clear yet. One of the possible mechanisms is developed by Hendriksen et al. [72], who proposes that formation and annealing of surface atomic steps is a driving force for the reduction-oxidation of palladium during oscillations in the oxidation of $\mathrm{CO}$ at near atmospheric pressure. Using operando X-ray diffraction technique, they identify the processes of smoothening of the metal surface and roughening of the oxide surface during inactive and active half-periods of the oscillations, respectively. These findings are supported by thermodynamic calculations, which indicate that, if the metallic surface becomes smoother, the metal-to-oxide phase transition is energetically advantageous. It should be underlined that these observations and interpretation of the kinetic oscillations are in disagreement with existing models of the rate oscillations observed in the oxidation of $\mathrm{CO}$ over Pt-group metals, because it is suggested that the metal surface is characterized by a low activity while the thin oxide layer over $\operatorname{Pd}(110)$ is characterized by a high activity. Moreover, Zhu et al. [73] studied the oxidation of $\mathrm{Pt}(111)$ and $\mathrm{Pt}(557)$ by high-pressure scanning tunneling microscopy and ambient-pressure XPS and found that low-coordinated step atoms are more active than terrace sites in the reactions with $\mathrm{O}_{2}$. They showed that the step sites are the nucleation centers for the formation of surface oxide clusters.

It is more probably that dissolved or subsurface oxygen in metallic nickel and/or defects in $\mathrm{NiO}$ play an important role for the feedback mechanism of kinetic oscillations in the oxidation of propane. We can speculate that the transition between the high-active and low-active states in this catalytic reaction proceeds through some transient states, which are similar to a solid solution of oxygen in metallic nickel or to highly defective nickel oxide. Earlier, Rodriguez et al. [74] have studied the reduction of $\mathrm{NiO}$ by hydrogen and they have shown a direct transformation $\mathrm{NiO} \rightarrow \mathrm{Ni}$ without accumulation of any intermediate phases. However, a perfect $\mathrm{NiO}(100)$ surface, the most common face of nickel oxide, exhibits a negligible reactivity toward $\mathrm{H}_{2}$ and the reduction of $\mathrm{NiO}$ starts after some induction period. During the induction period, surface defect sites (oxygen vacancies) are created that provide a high efficiency for the dissociation of $\mathrm{H}_{2}$. The presence of these oxygen vacancies leads to an increase in the adsorption energy of $\mathrm{H}_{2}$ and substantially lowers the energy barrier associated with the cleavage of the $\mathrm{H}-\mathrm{H}$ bond. At the 
same time, adsorbed hydrogen can induce the migration of oxygen vacancies from the bulk to the surface of the oxide. In our case, appearance of the defects in nickel oxide can facilitate the heterolytic activation of a $\mathrm{C}-\mathrm{H}$ bond of propane (the key step in the Mars-van Krevelen mechanism) increasing the rate of propane interaction with lattice oxygen. The fast removal of oxygen can reduce $\mathrm{NiO}$ to $\mathrm{Ni}$. The solid solution of oxygen in metallic nickel above a critical level can lead to the back transformation of the surface layers to nickel oxide. Some additional experiments with an X-ray diffraction technique or EXAFS are needed for the elucidation of this mechanism in detail.

\section{Conclusions}

We have investigated the evolution of self-sustained rate oscillations in the catalytic oxidation of propane over a nickel foil using in situ time-resolved X-ray photoelectron spectroscopy coupled with on-line mass spectrometry and gas chromatography. In addition, changes in the effective surface area and in the catalyst morphology under reaction conditions have been examined by scanning electron microscopy and a krypton adsorption technique. Using this combined approach, we have shown that the driving mechanism for the self-sustained kinetic oscillations is periodic bulk reoxidation of nickel. The high-active catalyst surface is represented by metallic nickel, whereas it is covered with a thick layer of NiO during the lowactive half-periods. On the metallic surface, the oxidation of propane proceeds via the LangmuirHinshelwood mechanism, while over the oxidized surface, the reaction proceeds via the Marsvan Krevelen redox mechanism. The periodic reduction and oxidation of nickel leads to a formation of a rough and porous structure of the nickel foil surface with a thickness of approximately $10-20 \mu \mathrm{m}$. This process is accompanied with approximately an 80 -fold increase in the effective surface area. This effect provokes a long induction period that is characterized by the low activity of the catalyst, after which the regular oscillations with high amplitude arise. We believe that without such reconstruction, the self-sustained rate oscillations in the catalytic oxidation of light hydrocarbons over catalysts with a low specific surface area (single crystals, foils, or wires) cannot arise because of low activity of these catalysts. Considering the oxidation of propane as a case reaction, we suppose that the self-sustained kinetic oscillations in the oxidation of other light alkanes over transition metals (such as $\mathrm{Ni}$ and $\mathrm{Co}$ ) proceed via a similar mechanism.

These results further demonstrate both the importance of time-resolved in situ measurements to gain insight into oscillated catalytic systems and the potential power of the combination of multiple experimental techniques.

\section{Acknowledgments}


The work was partially supported by the Based budget project V.44.1.16. S.S.K. is also thankful to the Ministry of Education and Science of the Russian Federation (project No 14.621.21.0004). The authors are grateful to the staff of BESSY II for their support during the beamtime.

\section{Appendix A. Supplementary material}

Supplementary data associated with this article can be found, in the on-line version, at http:// 


\section{References}

[1] G. Ertl, Adv. Catal. 37 (1990) 213.

[2] F. Schüth, B.E. Henry, L.D. Schmidt, Adv. Catal. 39 (1993) 51.

[3] M.M. Slinko, N.I. Jaeger, Stud. Surf. Sci. Catal. 86 (1994) 1.

[4] R. Imbihl, G. Ertl, Chem. Rev. 95 (1995) 697.

[5] X. Zhang, D.M.P. Mingos, D.O. Hayward, Catal. Lett. 72 (2001) 147.

[6] X. Zhang, D.O. Hayward, D.M.P. Mingos, Catal. Lett. 83 (2002) 149.

[7] X. Zhang, D.O. Hayward, D.M.P. Mingos, Catal. Lett. 86 (2003) 235.

[8] Y.P. Tulenin, M.Y. Sinev, V.V. Savkin, V.N. Korchak, Catal. Today 91-92 (2004) 155.

[9] X. Zhang, C.S.-M. Lee, D.O. Hayward, D.M.P. Mingos, Catal. Today 105 (2005) 283.

[10] X. Tang, Y. Nan, F. Huang, X. Zhang, Reac. Kinet. Mech. Cat. 107 (2012) 245.

[11] X. Zhang, C.S.-M. Lee, D.M.P. Mingos, D.O. Hayward, Appl. Catal. A 248 (2003) 129.

[12] V.Y. Bychkov, Y.P. Tyulenin, M.M. Slinko, V.N. Korchak, Appl. Catal. A 321 (2007) 180.

[13] D. König, W.H. Weber, B.D. Poindexter, J.R. McBride, G.W. Graham, K. Otto, Catal. Lett. 29 (1994) 329.

[14] Y. Deng, T.G. Nevell, J. Mol. Catal. A 142 (1999) 51.

[15] G.W. Graham, D. König, B.D. Poindexter, J.T. Remillard, W.H. Weber, Top. Catal. 8 (1999) 35.

[16] X. Zhang, C.S.-M. Lee, D.M.P. Mingos, D.O. Hayward, Appl. Catal. A 240 (2003) 183.

[17] Y. Liu, W.P. Fang, W.Z. Weng, H.L. Wan, J. Mol. Catal. A 239 (2005) 193.

[18] J.-M. Li, F.-Y. Huang, W.-Z. Weng, X.-Q. Pei, C.-R. Luo, H.-Q. Lin, C.-J. Huang, H.-L. Wan, Catal. Today 131 (2008) 179.

[19] M. Wang, W. Weng, H. Zheng, X. Yi, C. Huang, H. Wan, J. Nat. Gas Chem. 18 (2009) 300.

[20] V.Y. Bychkov, Y.P. Tyulenin, M.M. Slinko, V.N. Korchak, Catal. Lett. 119 (2007) 339.

[21] V.Y. Bychkov, Y.P. Tyulenin, M.M. Slinko, V.N. Korchak, Catal. Lett. 141 (2011) 602.

[22] A.Y. Gladky, V.K. Ermolaev, V.N. Parmon, Catal. Lett. 77 (2001) 103.

[23] A.Y. Gladky, V.V. Kaichev, V.K. Ermolaev, V.I. Bukhtiyarov, V.N. Parmon, Kinet. Catal. 46 (2005) 251.

[24] C. Kokkofitis, M. Stoukides, J. Catal. 243 (2006) 428.

[25] V.V. Kaichev, A.Y. Gladky, I.P. Prosvirin, A.A. Saraev, M. Hävecker, A. Knop-Gericke, R. Schlögl, V.I. Bukhtiyarov, Surf. Sci. 609 (2013) 113.

[26] B. Kimmerle, A. Baiker, J.-D. Grunwaldt, Phys. Chem. Chem. Phys. 12 (2010) 2288.

[27] J. Stötzel, R. Frahm, B. Kimmerle, M. Nachtegaat, J.-D. Grunwaldt, J. Phys. Chem. C 116 (2012) 599.

[28] V.I. Bukhtiyarov, V.V. Kaichev, I.P. Prosvirin, Top. Catal. 32 (2005) 3.

[29] A. Knop-Gericke, E. Kleimenov, M. Hävecker, R. Blume, D. Teschner, S. Zafeiratos, R. Schlögl, V.I. Bukhtiyarov, V.V. Kaichev, I.P. Prosvirin, A.I. Nizovskii, H. Bluhm, A. Barinov, P. Dudin, M. Kiskinova, Adv. Catal. 52 (2009) 213.

[30] N. Fairley, www.casaxps.com

[31] L.A. Giannuzzi, F.A. Stevie, Micron 30 (1999) 197.

[32] C.P. Li, A. Proctor, D.M. Hercules, Appl. Spectrosc. 38 (1984) 880.

[33] M.C. Biesinger, L.W.M. Lau, A.R. Gerson, R.S.C. Smart, Phys. Chem. Chem. Phys. 14 (2012) 2434.

[34] S.-J. Oh, J.W. Allen, I. Lindau, J. J.C. Mikkelsen, Phys. Rev. B 26 (1982) 4845.

[35] G.A. Rizzi, M. Petukhov, M. Sambi, G. Granozzi, Surf. Sci. 522 (2003) 1.

[36] A.V. Matveev, V.V. Kaichev, A.A. Saraev, V.V. Gorodetskii, A. Knop-Gericke, V.I. Bukhtiyarov, B.E. Nieuwenhuys, Catal. Today 244 (2015) 29.

[37] M.A. van Veenendaal, G.A. Sawatzky, Phys. Rev. Lett. 70 (1993) 2459.

[38] D. Alders, F.C. Voogt, T. Hibma, G.A. Sawatzky, Phys. Rev. B 54 (1996) 7716.

[39] N.S. McIntyre, M.G. Cook, Anal. Chem. 47 (1975) 2208.

[40] A.F. Carley, S.D. Jackson, J.N. O'Shea, M.W. Roberts, Surf. Sci. 440 (1999) L868.

[41] J.C. de Jesus, J. Carrazza, P. Pereira, F. Zaera, Surf. Sci. 397 (1997) 34. 
[42] G.T. Tyuliev, K.L. Kostov, Phys. Rev. B 60 (1999) 2900.

[43] A. Nagy, G. Mestl, T. Rühle, G. Weinberg, R. Schlögl, J. Catal. 179 (1998) 548.

[44] A.J. Nagy, G. Mestl, D. Herein, G. Weinberg, K. Kitzelmann, R. Schlögl, J. Catal. 182 (1999) 417.

[45] T. Brandstetter, T. Wagner, M. Oehzelt, P. Zeppenfeld, Surf. Sci. 603 (2009) 3410.

[46] O. Nilsen, A. Kjekshus, H. Fjellvag, Appl. Catal. A 207 (2001) 43.

[47] L. Hannevold, O. Nilsen, A. Kjekshus, H. Fjellvag, Appl. Catal. A 284 (2005) 163.

[48] V. Zielasek, B. Jürgens, C. Schulz, J. Biener, M.M. Biener, A.V. Hamza, M. Bäumer, Angew. Chem. Int. Ed. 45 (2006) 8241.

[49] R. Zeis, T. Li, K. Sieradzki, J. Snyder, J. Erlebacger, J. Catal. 253 (2008) 132.

[50] J. Yu, L. Zhang, B. Cheng, Y. Su, J. Phys. Chem. C 111 (2007) 10582.

[51] P. Corbo, F. Migliardini, Int. J. Hydrogen Energy 32 (2007) 55.

[52] G. Ertl, P.R. Norton, J. Rüstig, Phys. Rev. Lett. 49 (1982) 177.

[53] W. Tappe, U. Korte, G. Meyer-Ehmsen, Surf. Sci. 388 (1997) 162.

[54] S.B. Vendelbo, C.F. Elkjaer, H. Falsig, I. Puspitasari, P. Dona, L. Mele, B. Morana, B.J. Nelissen, R. van Rijn, J.F. Creemer, P.J. Kooyman, S. Helveg, Nature Mater. 13 (2014) 884.

[55] V.A. Burrows, S. Sundaresan, Y.J. Chabal, S.B. Christman, Surf. Sci. 160 (1985) 122.

[56] N.A. Collins, S. Sundaresan, Y.J. Chabal, Surf. Sci. 180 (1987) 136.

[57] S.J.A. Figueroa, M.A. Newton, J. Catal. 312 (2014) 69.

[58] B.C. Sales, J.E. Turner, M.B. Maple, Surf. Sci. 114 (1982) 381.

[59] B.L.M. Hendriksen, S.C. Bobaru, J.W.M. Frenken, Catal. Today 105 (2005) 234.

[60] Y.-Y. Chung, F. Aksoy, M.E. Grass, H. Kondoh, P.R. Jr., Z. Liu, B.S. Mun, Surf. Sci. 603 (2009) L35.

[61] M.R. Bassett, R. Imbihl, J. Chem. Phys. 93 (1990) 811.

[62] E.A. Lashina, V.V. Kaichev, N.A. Chumakova, V.V. Ustugov, G.A. Chumakov, V.I. Bukhtiyarov, Kinet. Catal. 53 (2012) 374.

[63] J.F. Weaver, Chem. Rev. 113 (2013) 4164.

[64] N.M. Martin, M. Van den Bossche, A. Hellman, H. Grönbeck, C. Hakanoglu, J. Gustafson, S. Blomberg, N. Johansson, Z. Liu, S. Axnanda, J.F. Weaver, E. Lundgren, ACS Catal. 4 (2014) 3330 .

[65] A.Y. Stakheev, A.M. Batkin, N.S. Teleguina, G.O. Bragina, V.I. Zaikovsky, I.P. Prosvirin, A.K. Khudorozhkov, V.I. Bukhtiyarov, Top. Catal. 56 (2013) 306.

[66] V.V. Kaichev, A.V. Miller, I.P. Prosvirin, V.I. Bukhtiyarov, Surf. Sci. 606 (2012) 420.

[67] A.V. Miller, V.V. Kaichev, I.P. Prosvirin, V.I. Bukhtiyarov, J. Phys. Chem. C 117 (2013) 8189.

[68] V.V. Kaichev, G.Y. Popova, Y.A. Chesalov, A.A. Saraev, D.Y. Zemlyanov, S.A. Beloshapkin, A. Knop-Gericke, R. Schlogl, T.V. Andrushkevich, V.I. Bukhtiyarov, J. Catal. 311 (2014) 59.

[69] V.P. Zhdanov, B. Kasemo, Phys. Rev. B 55 (1997) 4105.

[70] S.Y. Yamamoto, C.M. Surko, M.B. Maple, J. Chem. Phys. 103 (1995) 8209.

[71] M. Kim, M. Bertram, M. Poollmann, A. von Oertzen, A.S. Mikhailov, H.H. Ritermund, G. Ertl, Science 292 (2001) 1357.

[72] B.L.M. Hendriksen, M.D. Ackermann, R. van Rijn, D. Stoltz, I. Popa, O. Balmes, A. Resta, D. Wermeille, R. Felici, S. Ferrer, J.W.M. Frenken, Nature Chem. 2 (2010) 730.

[73] Z. Zhu, F. Tao, F. Zheng, R. Chang, Y. Li, L. Heinke, Z. Liu, M. Salmeron, G.A. Somorjai, Nano Lett. 12 (2012) 1491.

[74] J.A. Rodriguez, J.C. Hanson, A.I. Frenkel, J.Y. Kim, M. Pérez, J. Am. Chem. Soc. 124 (2002) 346. 


\section{Figure Captions}

Fig. 1. Evolution of self-sustained rate oscillations in the oxidation of propane over nickel: conversions of propane and oxygen measured by GC are presented in the top panel; the yield of $\mathrm{H}_{2}$ detected by MS is presented in the low panel. The oxygen flow is $0.5 \mathrm{sccm}$, the propane flow is $4.5 \mathrm{sccm}$, and the total pressure is 0.5 mbar. Labels 2, 3, 4, and 5 refer to the moments when the corresponding core-level spectra depicted in Fig. 2 were measured.

Fig. 2. Normalized $\mathrm{Ni} 2 p_{3 / 2}$ and O1s core-level spectra obtained in vacuum after the Ar-ions sputtering (1), under the reactant mixture flow at room temperature (2), after heating to $680{ }^{\circ} \mathrm{C}$ in the reactant mixture (3), in moments of low (near 2\%) conversion of propane (4) and high (near 18\%) conversion of propane (5) after the oscillations commence (see Fig. 1).

Fig. 3. Normalized $\mathrm{Ni} 2 p$ and $\mathrm{O} 1 \mathrm{~s}$ core-level spectra of a clean $\mathrm{Ni}$ foil, a NiO film obtained by the oxidation of the $\mathrm{Ni}$ foil in 1 bar $\mathrm{O}_{2}$ at $300^{\circ} \mathrm{C}$ for $10 \mathrm{~min}$, and bulk $\mathrm{Ni}(\mathrm{OH})_{2}$. The $\mathrm{Ni}$ foil was cleaned by repeated cycles of Ar-ion sputtering and subsequent annealing in vacuum at $600{ }^{\circ} \mathrm{C}$. The spin-orbit splitting in the $\mathrm{Ni} 2 p$ spectra of $\mathrm{Ni}^{0}, \mathrm{NiO}$, and $\mathrm{Ni}(\mathrm{OH})_{2}$ is $17.2,17.6$, and $17.8 \mathrm{eV}$, respectively.

Fig. 4. Self-sustained oscillations of the integral intensity of the O1s spectra observed simultaneously with the oscillations of gas-phase $\mathrm{CO}$ and $\mathrm{O}_{2}$ during the oxidation of propane over a $\mathrm{Ni}$ foil. The propane/oxygen ratio is $9 / 1$, the total pressure is $0.5 \mathrm{mbar}$, and the average temperature is approximately $610^{\circ} \mathrm{C}$.

Fig. 5. Characteristic plan-view (a, b, c) and cross-sectional (d) SEM images of a nickel foil used as a catalyst of the oxidation of propane during 2 hours; the propane/oxygen ratio is $9 / 1$, the total pressure is 5 mbar, and the average temperature is approximately $740{ }^{\circ} \mathrm{C}$.

Fig. 6. Characteristic SEM images of nickel foils used as a catalyst for the oxidation of propane during $40(\mathrm{a}, \mathrm{b}, \mathrm{c}), 130(\mathrm{~d}, \mathrm{e}, \mathrm{f})$, and $260 \mathrm{~min}(\mathrm{~g}, \mathrm{~h}, \mathrm{i})$; the propane/oxygen ratio is $9 / 1$, the total pressure is $5 \mathrm{mbar}$, and the average temperature is approximately $710{ }^{\circ} \mathrm{C}$. 


\section{Table Captions}

Table 1 Conversion of propane $(\mathrm{X})$, selectivity toward the main reaction products measured by GC simultaneously with the MS data presented in Fig. 1, and the chemical state of the catalyst. 


\section{Table 1}

Conversion of propane $(\mathrm{X})$, selectivity toward the main reaction products measured by GC simultaneously with the MS data presented in Fig. 1, and the chemical state of the catalyst.

\begin{tabular}{|c|c|c|c|c|c|}
\hline \multirow{2}{*}{ Time, min } & \multirow{2}{*}{$\mathrm{X}, \%$} & \multicolumn{3}{|c|}{ Selectivity, \% } & \multirow{2}{*}{ Catalyst state $^{1}$} \\
\hline & & $\mathrm{CO}$ & $\mathrm{C}_{3} \mathrm{H}_{6}$ & $\mathrm{CO}_{2}$ & \\
\hline 10.2 & 0.6 & 43.9 & 40.3 & 15.8 & oxide $^{2}$ \\
\hline 39.8 & 0.1 & 20.6 & 42.2 & 37.2 & oxide \\
\hline 55.8 & 0.3 & 27 & 36.1 & 36.9 & oxide \\
\hline 78.5 & 0.5 & 36.9 & 29.9 & 33.2 & oxide \\
\hline 113.6 & 0.7 & 34.5 & 40.9 & 24.6 & oxide \\
\hline 146.6 & 0.9 & 41.9 & 38.1 & 20 & oxide \\
\hline 163.4 & 1 & 38.2 & 42 & 19.8 & oxide \\
\hline 256.7 & 1.5 & 45.4 & 38.7 & 16 & oxide \\
\hline 278.3 & 1.9 & 61.2 & 25.9 & 12.9 & oxide \\
\hline 325.4 & 1.8 & 53.3 & 33.1 & 13.6 & oxide \\
\hline 346.9 & 19.6 & 96.3 & 1.0 & 2.7 & metal \\
\hline 368.9 & 2.3 & 59.4 & 27 & 13.5 & oxide \\
\hline 397.9 & 1.6 & 65.2 & 23.2 & 11.6 & oxide \\
\hline 457.3 & 2.1 & 64.5 & 24.7 & 10.8 & oxide $^{3}$ \\
\hline 476.4 & 1.9 & 58.3 & 30 & 11.7 & oxide \\
\hline 570.4 & 18.1 & 97.7 & 1.0 & 1.3 & metal $^{4}$ \\
\hline 580.5 & 12.6 & 96.8 & 1.6 & 1.6 & metal/oxide \\
\hline 621 & 2.8 & 67.9 & 21.5 & 10.6 & oxide \\
\hline 641.9 & 22.9 & 96.8 & 1.5 & 1.7 & metal \\
\hline
\end{tabular}

determined by XPS;

$2,3,4$ in these moments the core-level spectra marked as 3, 4, and 5 in Fig. 2 are acquired. 

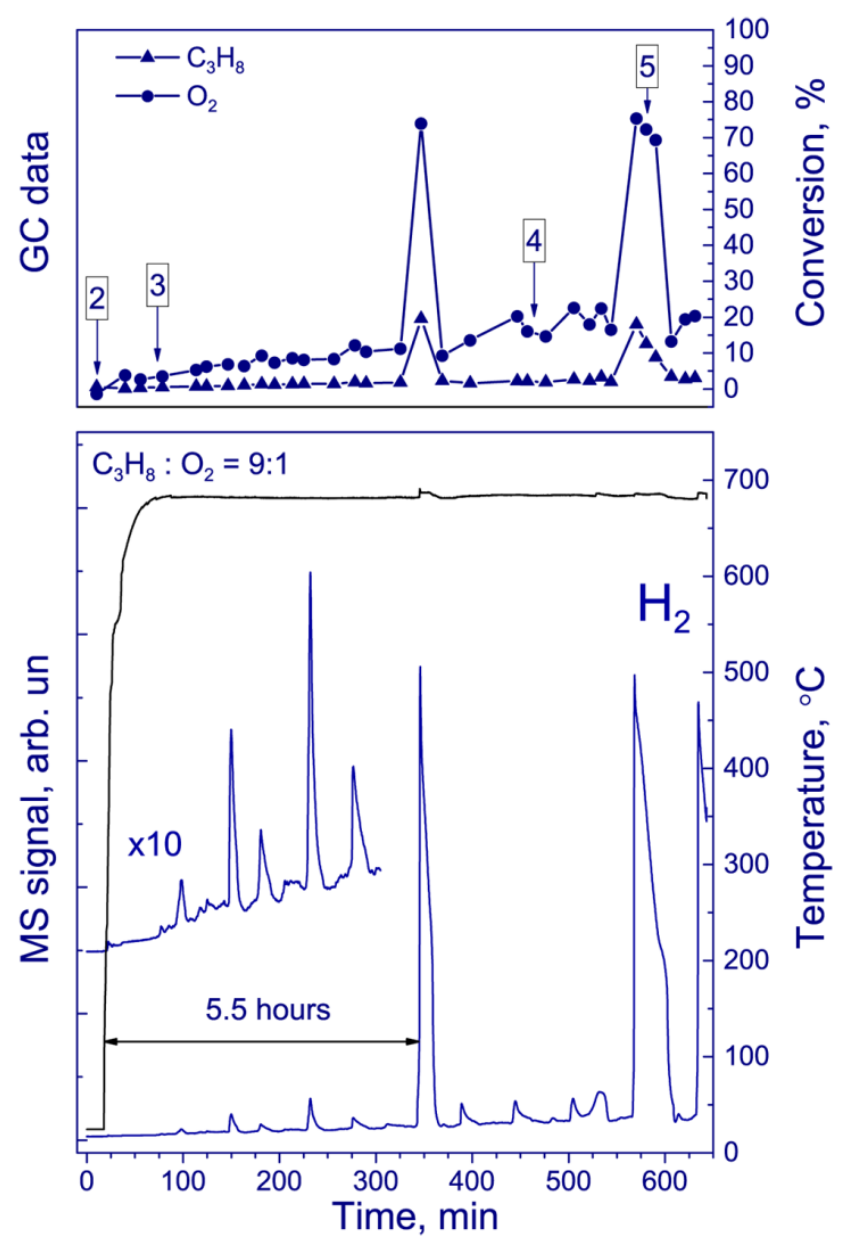

Fig. 1. Evolution of self-sustained rate oscillations in the oxidation of propane over nickel: conversions of propane and oxygen measured by GC are presented in the top panel; the yield of $\mathrm{H}_{2}$ detected by MS is presented in the low panel. The oxygen flow is $0.5 \mathrm{sccm}$, the propane flow is $4.5 \mathrm{sccm}$, and the total pressure is 0.5 mbar. Labels 2, 3, 4, and 5 refer to the moments when the corresponding core-level spectra depicted in Fig. 2 were measured. 


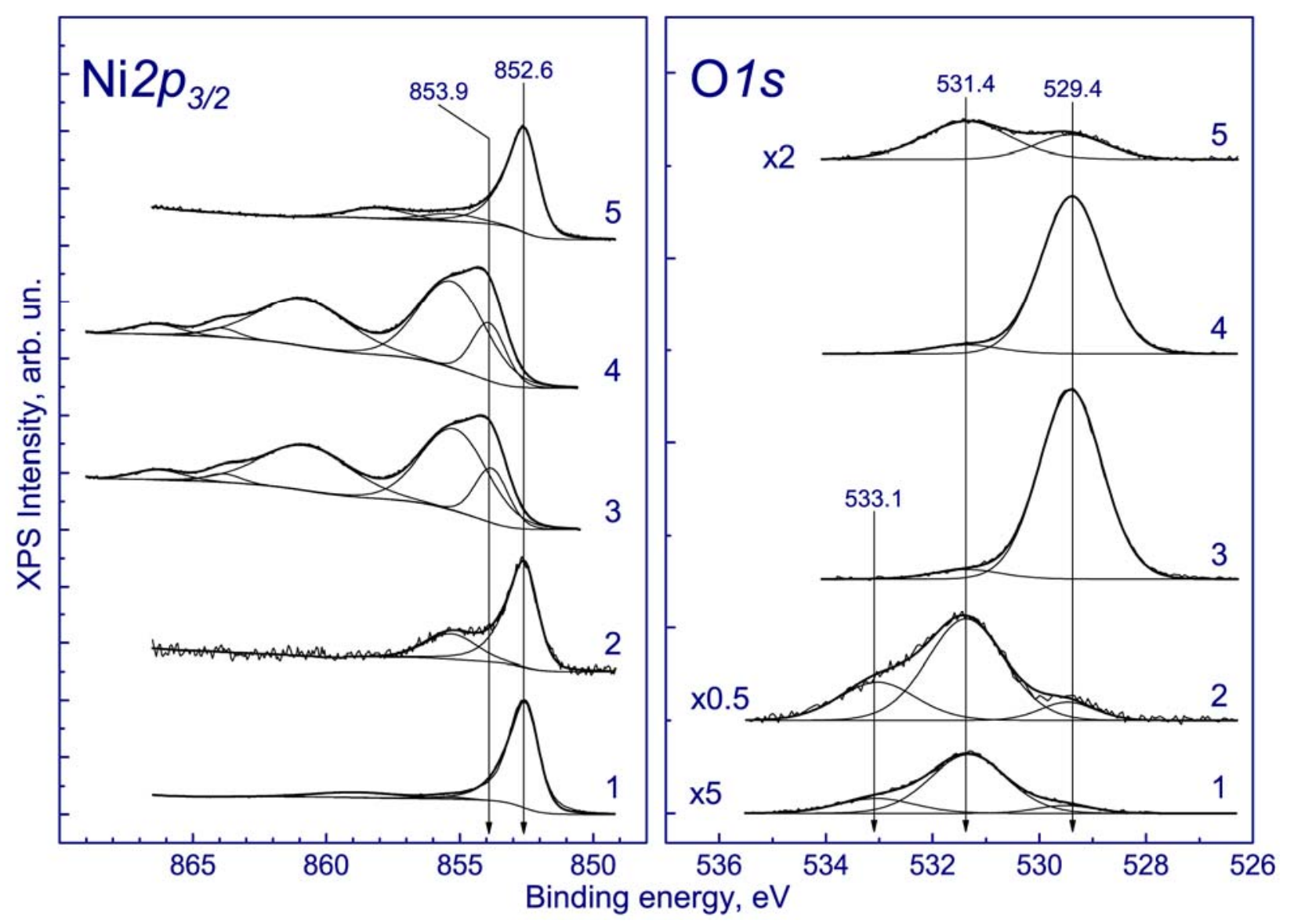

Fig. 2. Normalized $\mathrm{Ni} 2 p_{3 / 2}$ and $\mathrm{O} 1 s$ core-level spectra obtained in vacuum after the Ar-ions sputtering (1), under the reactant mixture flow at room temperature (2), after heating to $680{ }^{\circ} \mathrm{C}$ in the reactant mixture (3), in moments of low (near 2\%) conversion of propane (4) and high (near 18\%) conversion of propane (5) after the oscillations commence (see Fig. 1). 


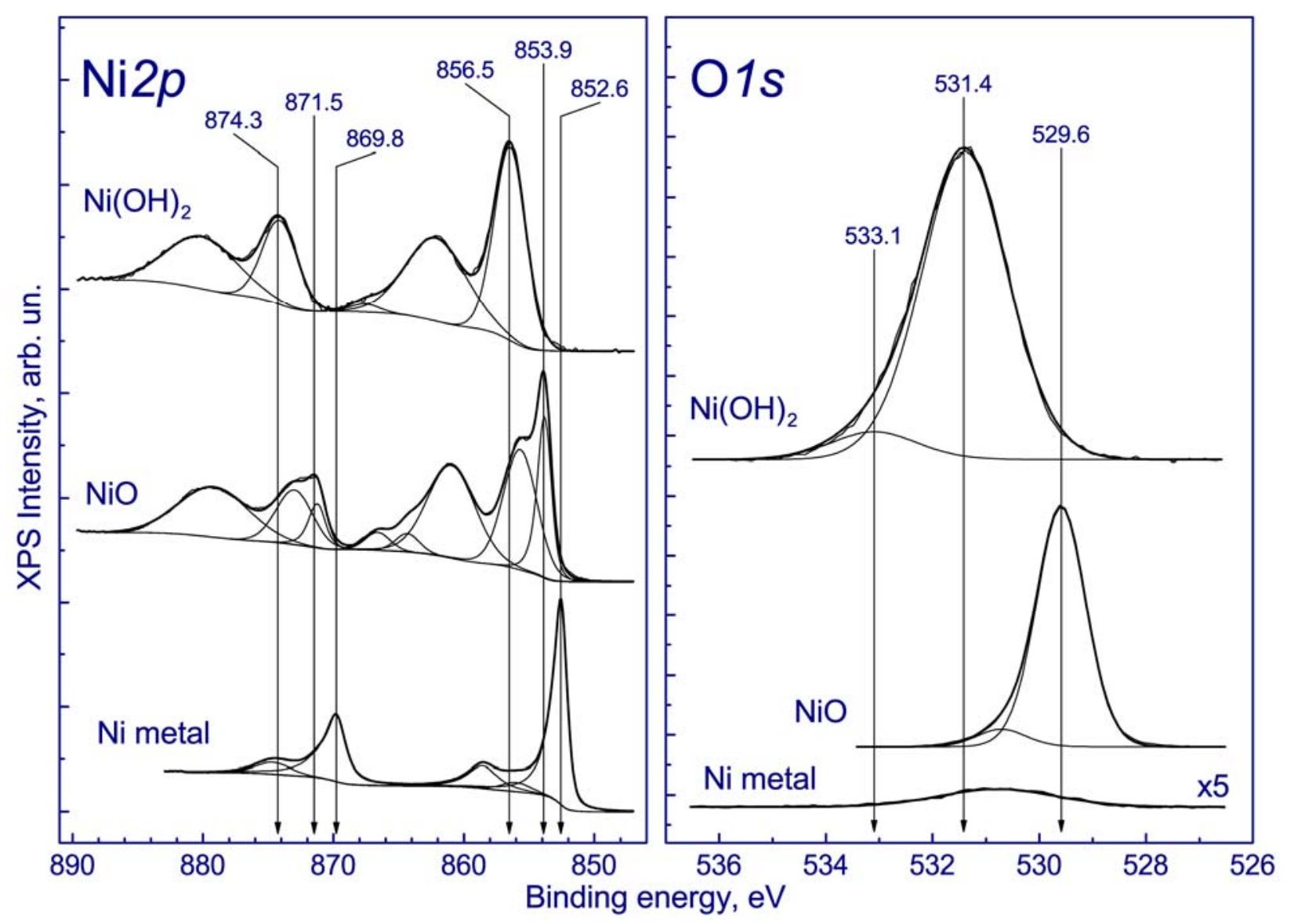

Fig. 3. Normalized Ni2p and $\mathrm{O} 1 s$ core-level spectra of a clean Ni foil, a NiO film obtained by the oxidation of the $\mathrm{Ni}$ foil in 1 bar $\mathrm{O}_{2}$ at $300{ }^{\circ} \mathrm{C}$ for $10 \mathrm{~min}$, and bulk $\mathrm{Ni}(\mathrm{OH})_{2}$. The $\mathrm{Ni}$ foil was cleaned by repeated cycles of Ar-ion sputtering and subsequent annealing in vacuum at $600{ }^{\circ} \mathrm{C}$. The spin-orbit splitting in the $\mathrm{Ni} 2 p$ spectra of $\mathrm{Ni}^{0}, \mathrm{NiO}$, and $\mathrm{Ni}(\mathrm{OH})_{2}$ is $17.2,17.6$, and $17.8 \mathrm{eV}$, respectively. 


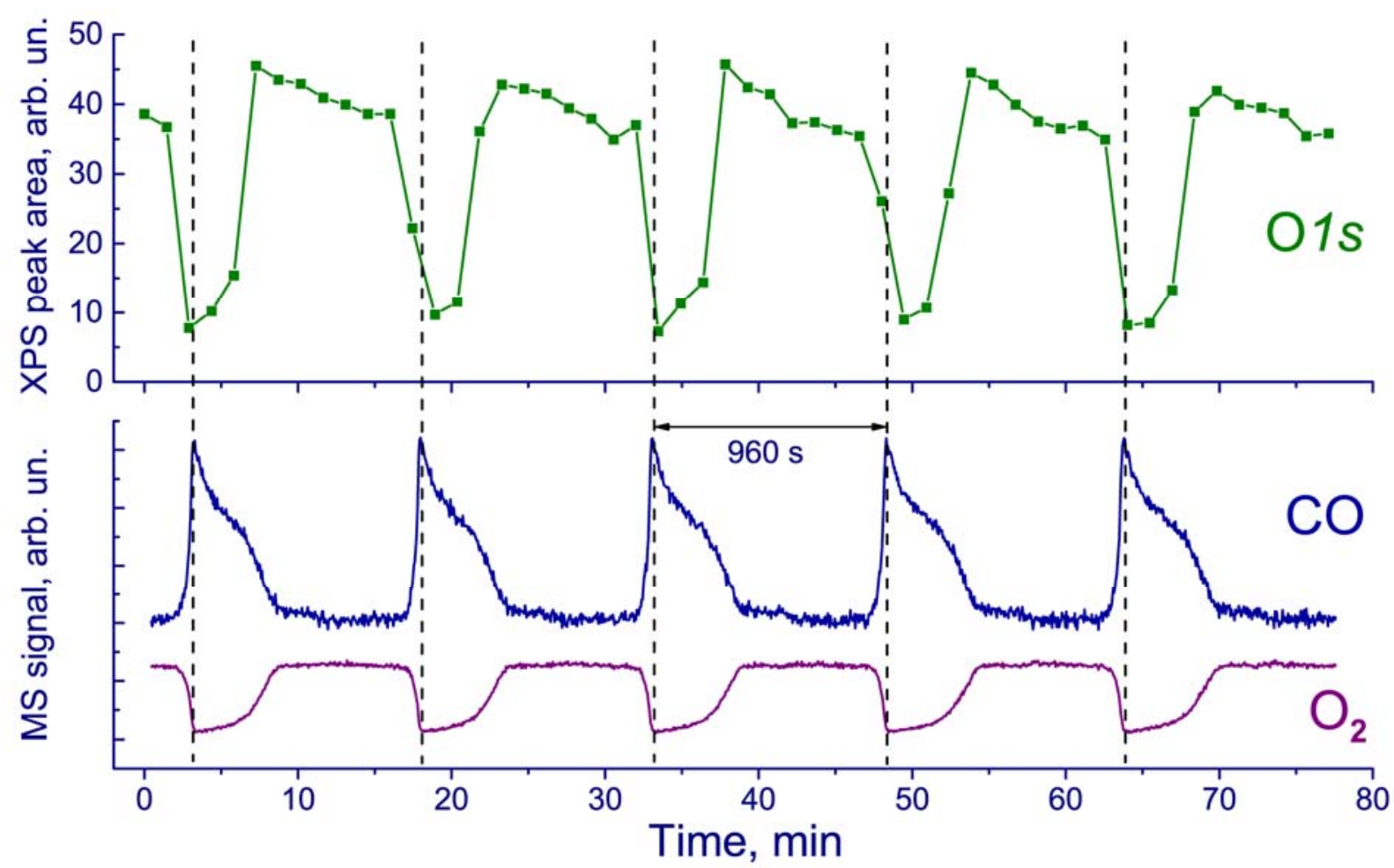

Fig. 4. Self-sustained oscillations of the integral intensity of the O1s spectra observed simultaneously with the oscillations of gas-phase $\mathrm{CO}$ and $\mathrm{O}_{2}$ during the oxidation of propane over a $\mathrm{Ni}$ foil. The propane/oxygen ratio is $9 / 1$, the total pressure is $0.5 \mathrm{mbar}$, and the average temperature is approximately $610^{\circ} \mathrm{C}$. 

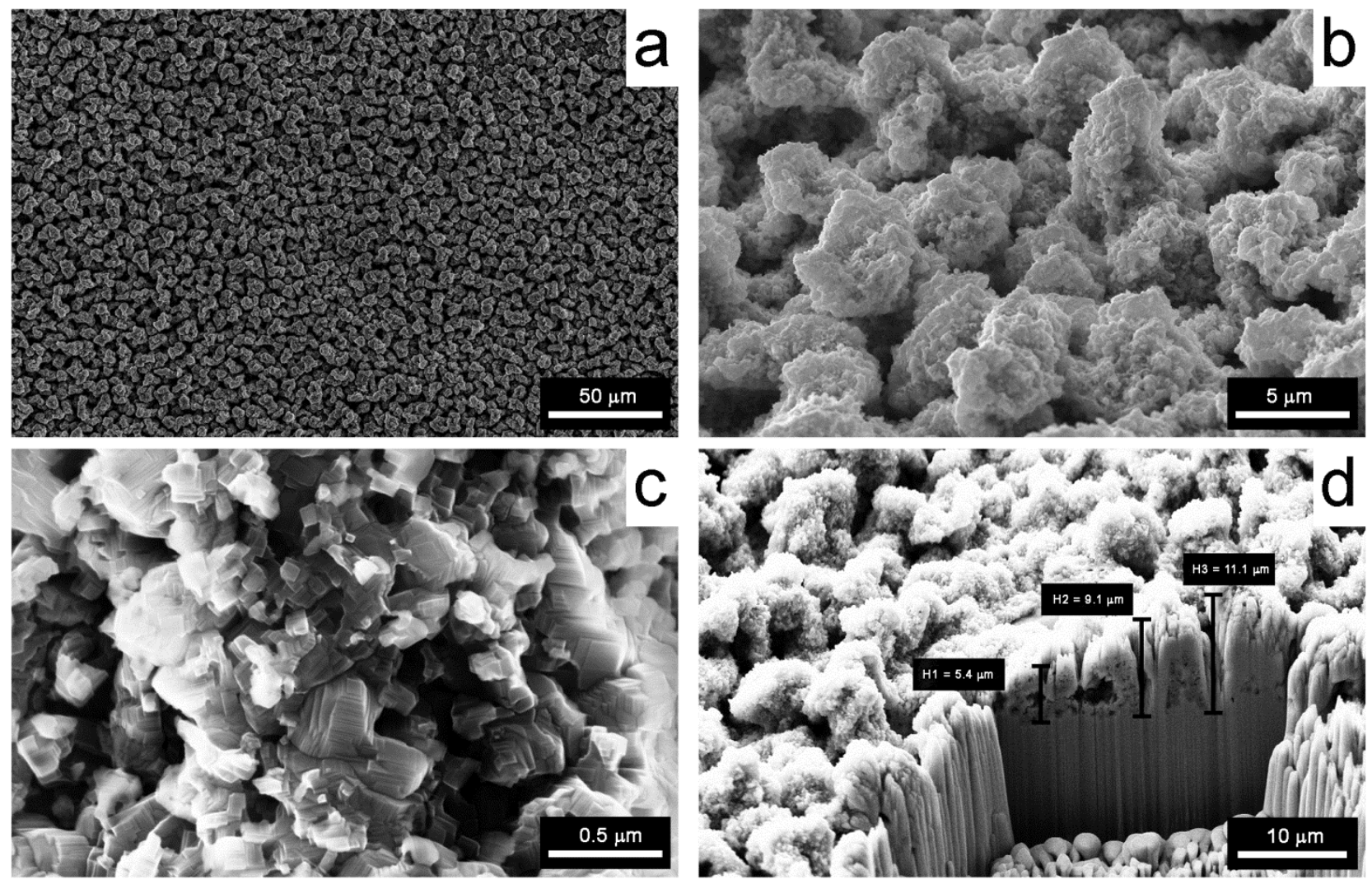

Fig. 5. Characteristic plan-view (a, b, c) and cross-sectional (d) SEM images of a nickel foil used as a catalyst of the oxidation of propane during 2 hours; the propane/oxygen ratio is $9 / 1$, the total pressure is 5 mbar, and the average temperature is approximately $740{ }^{\circ} \mathrm{C}$. 


\section{Sample 1}
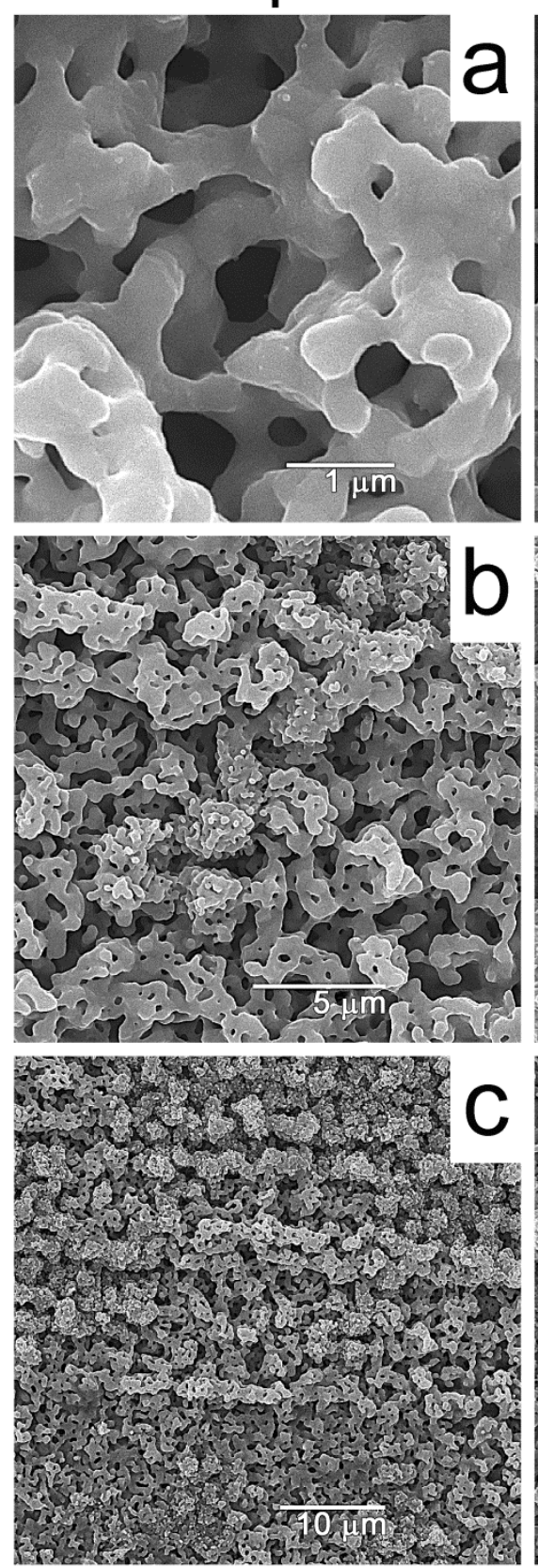

Sample 2
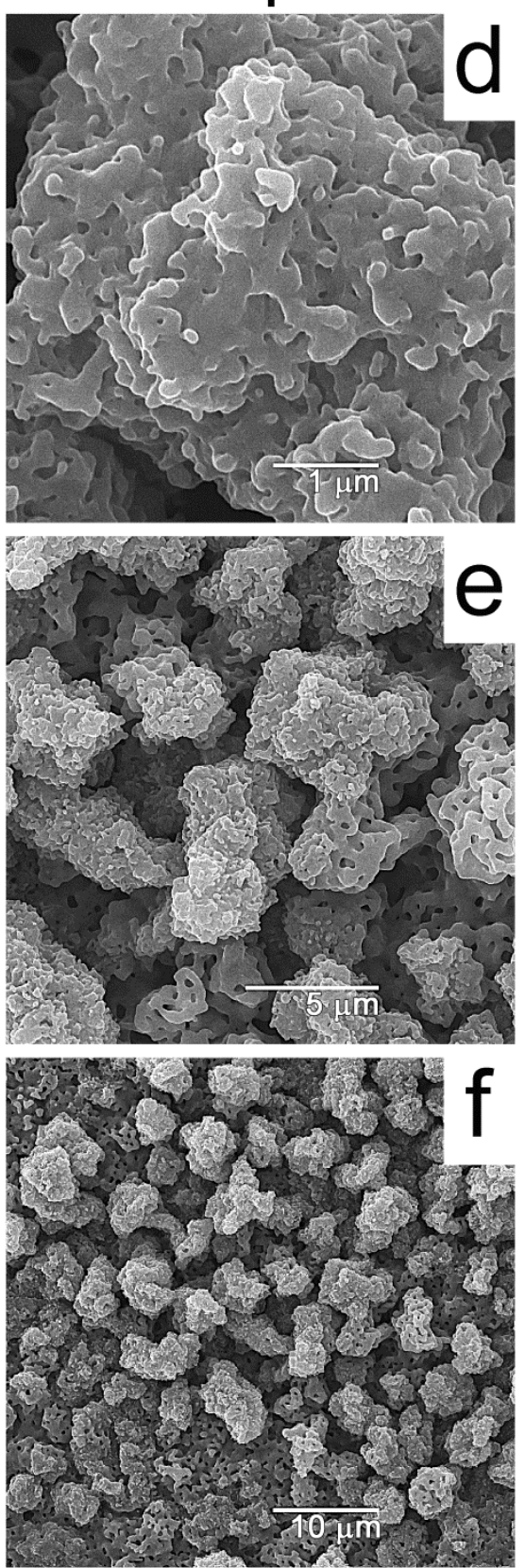

Sample 3
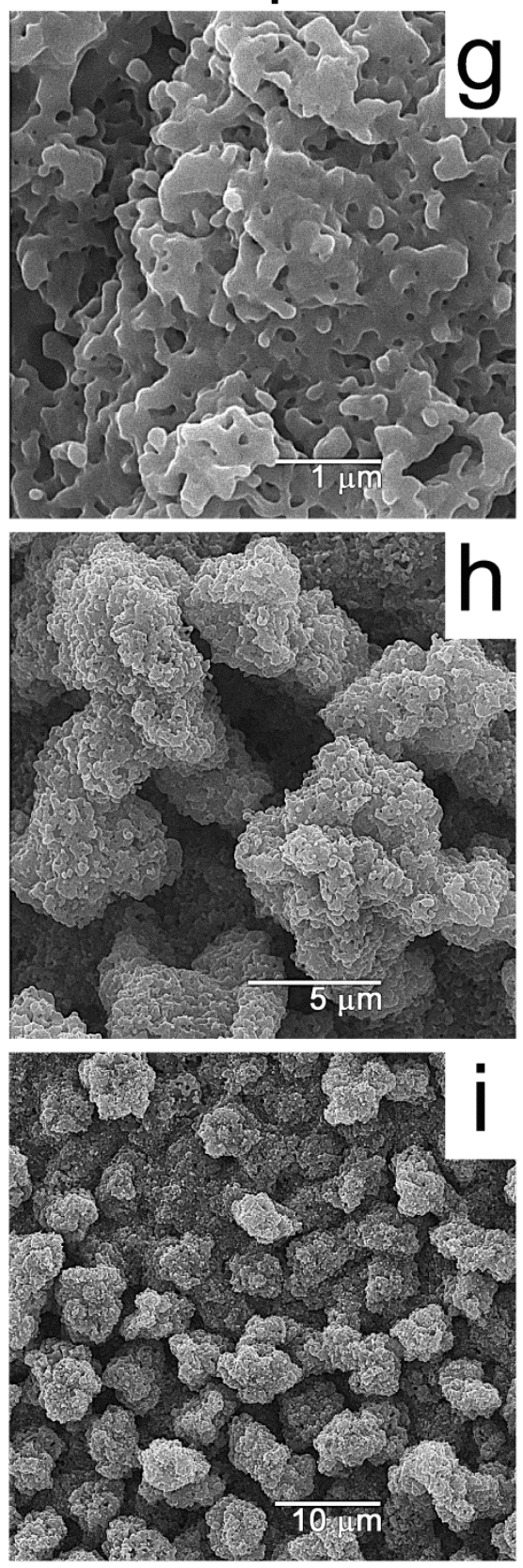

Fig. 6. Characteristic SEM images of nickel foils used as a catalyst for the oxidation of propane during $40(\mathrm{a}, \mathrm{b}, \mathrm{c}), 130(\mathrm{~d}, \mathrm{e}, \mathrm{f})$, and $260 \mathrm{~min}(\mathrm{~g}, \mathrm{~h}, \mathrm{i})$; the propane/oxygen ratio is $9 / 1$, the total pressure is $5 \mathrm{mbar}$, and the average temperature is approximately $710{ }^{\circ} \mathrm{C}$. 